\title{
Molecular epidemiology of Clostridium difficile in two tertiary care hospitals in Shandong Province, China
}

This article was published in the following Dove Press journal: Infection and Drug Resistance

\author{
Ying Luo 1,2 \\ Wen Zhang ${ }^{2}$ \\ Jing-Wei Cheng ${ }^{3}$ \\ Meng Xiao ${ }^{3}$ \\ Gui-Rong Sun' \\ Cheng-Jie Guo² \\ Ming-Jun Liu' \\ Pei-Shan Cong' \\ Timothy Kudinha ${ }^{4,5}$ \\ 'Department of Clinical Laboratory, \\ The Affiliated Hospital of Qingdao \\ University, Qingdao, China; \\ ${ }^{2}$ Department of Clinical Laboratory, \\ Zibo Central Hospital, Zibo, China; \\ ${ }^{3}$ Department of Clinical Laboratory, \\ Peking Union Medical College \\ Hospital, Chinese Academy of Medical \\ Sciences, Beijing, China; ${ }^{4}$ Charles Sturt \\ University, Orange, NSW, Australia; \\ ${ }^{5}$ Central West Pathology Laboratory, \\ Orange, NSW, Australia
}

Correspondence Gui-Rong Sun Department of Clinical Laboratory, The Affiliated Hospital of Qingdao University, 16, Jiangsu Road, Qingdao 266003, China Tel $+865328291 \quad 1780$

Fax $+865328291 \quad 1302$

Email sunguirong@hotmail.com
Purpose: The incidence and severity of Clostridium difficile infection (CDI) have markedly increased over the past decade. However, there is very limited epidemiological data on CDI in China so far, specifically no data in Shandong Province. The aim of this study was to evaluate diagnostic algorithm for CDI and to gain data on molecular epidemiology of CDI in the Shandong Province of China.

Materials and methods: Nonrepetitive unformed fecal specimens ( $\mathrm{n}=504)$ were investigated by the glutamate dehydrogenase $(\mathrm{GDH}), C$. difficile toxin A\&B (CDAB) tests and toxigenic culture. Furthermore, 85 isolates were characterized by toxin gene detection, multilocus sequence typing, ribotyping and antimicrobial susceptibility testing.

Results: The algorithm of combining GDH and CDAB tests could define diagnosis of $54.2 \%$ CDI cases and excluded $90 \%$ of non-CDI. Further adding the toxigenic culture to the algorithm enhanced the detection sensitivity to $100 \%$. Toxigenic strains comprised $84.7 \%$ of isolates, including A+B+CDT- $(71.8 \%, 61 / 85), \mathrm{A}-\mathrm{B}+\mathrm{CDT}-(11.8 \%, 10 / 85)$ and $\mathrm{A}+\mathrm{B}+\mathrm{CDT}+(1.2 \%$, $1 / 85)$ isolates. RT046/ST35 (13.9\%, 10/72), RT014/ST2 (12.5\%, 9/72) and RT017/ST37 $(12.5 \%, 9 / 72)$ were the more common genotypes among toxigenic $C$. difficile strains. The clinical

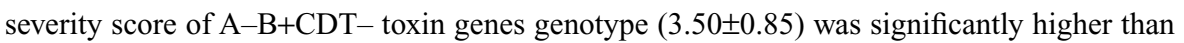
the $\mathrm{A}+\mathrm{B}+\mathrm{CDT}-$ type $(2.59 \pm 0.93)(P<0.05)$. RT046/ST35 isolates were highly prevalent and had high clinical severity scores $(3.80 \pm 0.92)$. Variations in resistance from different sequence types (STs) were observed. Toxigenic strains showed higher resistance rates to erythromycin, clindamycin and ciprofloxacin compared to nontoxigenic strains $(P<0.05)$.

Conclusion: The epidemiology of $C$. difficile in Shandong Province differed from other regions in China. Comprehensive optimized diagnosis strategy and continuous surveillance should be established and applied in order to curb the spread of toxigenic C. difficile strains, especially for hospitalized patients.

Keywords: Clostridium difficile, genotype, antimicrobial resistance, severity score, Shandong Province, China

\section{Introduction}

Clostridium difficile, a gram-positive sporulating anaerobic bacillus, is the etiologic pathogen of pseudomembranous colitis and a principal pathogen of antimicrobialassociated diarrhea. Patients with $C$. difficile infection (CDI) have clinical manifestations ranging from asymptomatic carriage, diarrhea to pseudomembranous colitis, even severe life-threatening toxic megacolon, sepsis and death. ${ }^{1}$ Generally, TcdA and TcdB toxins (encoded by $t c d A$ and $t c d B$ genes, respectively) are the major virulence factors produced by toxigenic $C$. difficile strains. However, some strains can also 
produce $C$. difficile binary toxin (CDT; encoded by binary genes $c d t A$ and $c d t B) .^{2}$

The increased morbidity and severity of CDI has led to a significant economic burden on the health care systems worldwide, with increased treatment cost and prolonged hospital stay. ${ }^{3,4} \mathrm{CDI}$ is thus regarded an urgent public health threat, and the financial burden is estimated to be $\$ 725$ million in community settings and $\$ 5.4$ billion in health care settings in North America. ${ }^{5}$ Knowledge of the antimicrobial susceptibility profiles and molecular types of $C$. difficile is important for monitoring spread of this organism. Of the typing methods described for $C$. difficile, multilocus sequence typing (MLST), which facilitates isolate discrimination by sequencing 7 housekeeping gene fragments, is widely used in studying the population gene structure and global epidemiology of the organism. ${ }^{6,7}$ However, at the present time, polymerase chain reaction (PCR) ribotyping is the most frequently used typing method because of the high discriminatory power and low costs. ${ }^{89}$ One of the most notable findings achieved by molecular epidemiology studies worldwide has been the detection of the hypervirulent $C$. difficile clone BI/NAP1/027 (BI: restriction endonuclease analysis group BI; NAP1: North American pulse-field type 1; PCR ribotype 027), which especially occurred in North America and Europe. ${ }^{10,11}$

In China, there is limited clinical and epidemiologic data on CDIs, with few case reports and studies described in only a few geographical regions, including Beijing, Shanghai, Zhejiang and Guangzhou. ${ }^{7,8,12-15}$ Shandong Province, the second largest populous province in China, covering an area of $155,800 \mathrm{~km}^{2}$ with a population of around 100 million, has no related report on CDIs to date.

This study, for the first time, evaluated the CDI laboratory diagnostic strategies and explored the molecular epidemiology of $C$. difficile strains from two hospitals in Shandong Province, aiming to provide local scientific reference data for prevention and control of CDI.

\section{Materials and methods Ethics}

The study was approved by the Human Research Ethics Committee of the Affiliated Hospital of Qingdao University. The written informed consent requirement from patients was waived due to the retrospective nature of the study. Furthermore, all patients' data was anonymized before the study.

\section{Study design and sample collection}

This study was conducted at the Zibo Central Hospital (ZCH) and the Affiliated Hospital of Qingdao University (AHQU), in Shandong Province in Eastern China. Both hospitals are tertiary general hospitals with 2000 beds. The study was conducted from March 2016 to April 2017. A total of 504 nonrepetitive unformed stool specimens were collected from hospitalized patients with suspected CDI symptoms during the study period (Figure 1).

\section{VIDAS glutamate dehydrogenase (GDH) and $C$. difficile toxin $A \& B(C D A B)$ testing}

All the fecal specimens were tested by enzyme immunoassay (EIA) methods using commercial VIDAS GDH and CDAB kits (bioMérieux, Marcy l'Etoile, France), following the manufacturer's instructions.

\section{C. difficile culture and identification}

The fecal samples were incubated on ChromID C. difficile agar (CDIF, bioMérieux) at $35^{\circ} \mathrm{C}$ under anaerobic condition for $48 \mathrm{~h}$. Typical $C$. difficile colonies were identified by matrix-assisted laser desorption/ionization time-of-flight mass spectrometry (MALDI-TOF MS) with VITEK MS system (bioMérieux).

\section{DNA extraction, toxin gene detection and $t c d C$ sequencing}

Genomic DNA was extracted, and a five-plex PCR was performed to simultaneously detect $16 \mathrm{~S}$ rDNA and toxin genes $t c d A$ (encoding toxin $\mathrm{A}$ ), $t c d B$ (encoding toxin $\mathrm{B}$ ), $c d t A$ and $c d t B$ in $C$. difficile isolates, as previously described. ${ }^{2}$ Isolates positive for toxin A were further characterized to check for the deletion of the repeating region of $t c d A$ gene by primers NK9 and NKV011. ${ }^{16}$ The $t c d C$ gene, a negative regulator of $t c d A$ and $t c d B$, was also sequenced and analyzed as previously described. ${ }^{17}$

\section{MLST and PCR ribotyping}

MLST was performed by using 7 gene loci ( $a d k, a t p A, d x r$, $\operatorname{gly} A, \operatorname{rec} A, \operatorname{sod} A$ and $t p i)$, as previously described. ${ }^{6}$ PCR products were purified and sequenced at Taihe Biotechnology Company (Beijing, China). DNA sequences were queried against the PubMLST database (http://pubmlst. org/cdifficile/) to obtain the allele numbers, sequence types (STs) and clades. Five novel STs identified in this study were submitted to the database and assigned ST numbers, ST450-ST454.

PCR ribotyping was performed by capillary gel electrophoresis as previously described. ${ }^{18}$ Gene Marker V2.2.0 (Soft Genetics, America) was used to determine the size of each peak, and ribotypes (RTs) were assigned by presenting the 


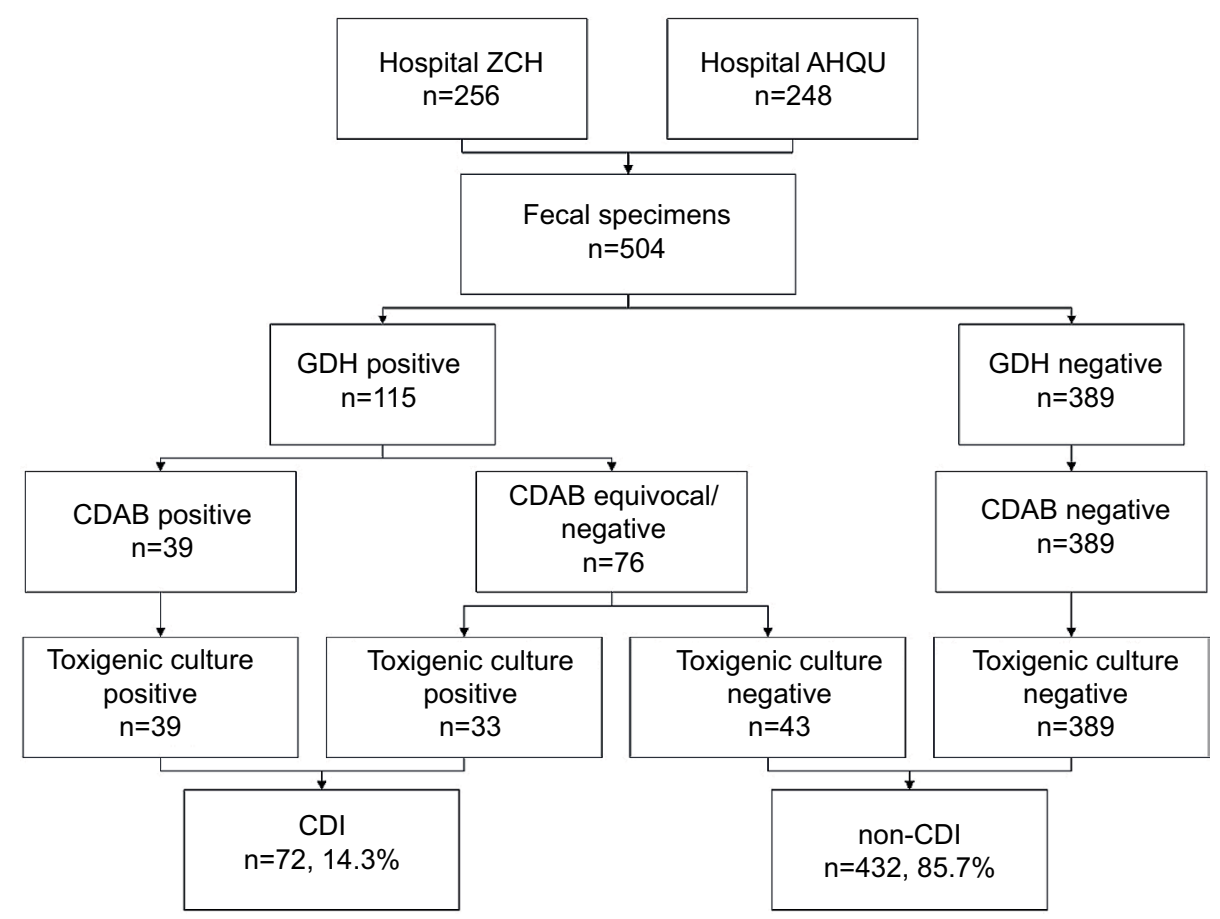

Figure I Flow diagram for the three-step algorithm to confirm toxigenic Clostridium difficile and the diagnosis of CDI.

Abbreviations: ZCH, Zibo Central Hospital; AHQU, the Affiliated Hospital of Qingdao University; GDH, glutamate dehydrogenase; CDAB, C. difficile toxin A\&B; CDI, C. difficile infection.

data on the WEBRIBO database (https://webribo.ages.at) and compared with results reported by Cheng et al. ${ }^{8}$ Novel RTs observed in this study were named as "SDR" plus two Arabic numbers (e.g., SDR01).

Three reference $C$. difficile strains, PUCD10 (PUR09/ ST81), PUCD301 (RT027/ST1) and PUCD610 (RT017/ ST37), were used as internal controls. ${ }^{9}$

\section{Antimicrobial susceptibility testing}

The agar dilution method was used to determine the minimum inhibitory concentrations (MICs) of vancomycin, metronidazole, erythromycin, clindamycin, ciprofloxacin and tetracycline, according to the Clinical and Laboratory Standards Institute (CLSI) guidelines M11-A8. ${ }^{19}$ The interpretation of breakpoints of metronidazole, clindamycin and tetracycline was based on CLSI M100-S27 criteria. ${ }^{20}$ In addition, the breakpoints of vancomycin, erythromycin and ciprofloxacin were $\geq 32, \geq 8$ and $\geq 8 \mathrm{mg} / \mathrm{L}$, respectively (Table S1). ${ }^{21} \mathrm{Bac}$ teroides fragilis ATCC 25285 was used for quality control.

\section{Resistance gene detection}

The quinolone resistance determining region (QRDR) of gyrA and $g y r B$ genes were amplified and sequenced in 30 selected ciprofloxacin-resistant isolates as previously described by Drudy et al. ${ }^{22}$

\section{Patient characteristics and severity score}

A CDI severity score was determined for each patient based on clinical features, laboratory test findings and clinical impressions of the attending physician, in accordance to the 2010 updated America guidelines. ${ }^{23}$ The severity of CDI in each patient was assigned a score of $1-6,1$, no clinical CDI; 2 , mild; 3 , mild to moderate; 4 , moderate; 5 , moderate to severe; and 6 , severe. ${ }^{7,23}$

\section{Statistical analysis}

All data were statistically analyzed by using SPSS software (version 18.0, IBM, New York, USA). Kruskal-Wallis and chi-square tests were used to analyze correlations among STs, RTs and antimicrobial susceptibility patterns of $C$. difficile strains. A $P$-value of $<0.05$ was considered statistically significant.

\section{Results \\ General clinical information}

A total of 504 inpatients with diarrhea from $\mathrm{ZCH}(\mathrm{n}=256)$ and AHQU ( $\mathrm{n}=248$ ) were included in this study (Figure 1). The average age of the patients, which included 261 males (51.8\%) and 243 females (48.2\%), was 49.3 \pm 18.1 (ranged from 4 to 91$)$. About $24.0 \%$ (121/504) of the patients were from hematology and oncology departments, 20.0\%(101/504) 
from gastroenterology department, 16.9\% (85/504) from surgery department, 7.9\% (40/504) from emergency department, 7.5\% (38/504) from intensive care unit, 6.2\% (31/504) from pediatric department and $17.5 \%(88 / 504)$ from other departments (i.e., geriatrics, obstetrics and gynecology, cardiovascular, neurology).

\section{Comparison of GDH versus toxigenic culture}

Among the 504 fecal specimens tested, 22.8\% (115/504) were positive for GDH, and 16.9\% (85/504) were C. difficile culture positive. Only one specimen was GDH negative but culture positive (Table 1; Figure 1). Compared to the culture method, the sensitivity, specificity, positive predictive value (PPV) and negative predictive value (NPV) of the GDH assay were $98.8 \%, 92.6 \%, 73.0 \%$ and $99.7 \%$, respectively (Table 2 ).

\section{Detection of toxin genes and comparison with CDAB EIA method}

Of the 85 C. difficile strains isolated in this study, 72 (84.7\%) were toxin gene positive, among which $61(71.8 \%)$ were $t c d A$ positive, $t c d B$-positive and $c d t A / c d t B$-negative (A+B+CDT-), and $10(11.8 \%)$ were $t c d A$-negative, $t c d B$-positive and $c d t A /$ $c d t B$-negative (A-B+CDT-). Only one strain (CD029) isolated in $\mathrm{ZCH}$ was $c d t$ gene positive, and the toxigenic type was $t c d A$-positive, $t c d B$-positive and $c d t A / c d t B$-positive $(\mathrm{A}+\mathrm{B}+\mathrm{CDT}+)($ Figure 2A; Table 1). The $t c d C$ gene in this isolate had an 18-bp deletion at nucleotide positions 330-347 and a single base pair deletion at nucleotide 117 .
Thirty-nine fecal specimens were CDAB positive and toxigenic culture positive (7.7\%). However, among $76 \mathrm{CDAB}$ negative/equivocal strains, 33 toxigenic culture positive strains were detected (43.4\%) (Figure 1). Therefore, a total of 72 out of 504 patients $(14.3 \%)$ with diarrhea were defined as CDI according to toxigenic culture results (Figure 1). Compared to toxigenic culture, the sensitivity, specificity, PPV and NPV of CDAB assay were $54.2 \%, 100.0 \%, 100.0 \%$ and $92.9 \%$, respectively (Table 2 ).

To overcome the deficiencies of low PPV for GDH and NPV for CDAB methods, we recommended a combined laboratory diagnosis algorithm for CDI based on GDH and CDAB testing and complemented by detection of toxin genes either in toxigenic culture method or directly in stool samples for any discordant results (Figure 1), as recommended by the European Society of Clinical Microbiology and Infectious Diseases (ESCMID). ${ }^{24}$

\section{Genotypes determined by MLST and PCR ribotyping}

The 85 C. difficile strains were classified into $23 \mathrm{STs}$, including 5 STs (1 per isolate) that were novel (Table 3). Among 72 toxigenic strains and 13 nontoxigenic strains, 20 and 4 STs were detected, respectively. Only ST3 comprised both toxigenic $(n=8)$ and non-toxigenic $(n=9)$ strains (Table 3$)$. Among toxigenic $C$. difficile strains, ST2 $(25.0 \%, 18 / 72)$ was the most common, followed by ST35 (18.1\%, 13/72), ST37 (12.5\%, 9/72), ST3 (11.1\%, 8/72) and ST54 (9.7\%, $7 / 72)$, while ST3 $(69.2 \%, 9 / 13)$ was the most common ST

Table I Clostridium difficile culture, VIDAS GDH, VIDAS CDAB and toxigenic typing results for 504 fecal samples in the study

\begin{tabular}{|c|c|c|c|c|c|c|c|}
\hline \multirow{2}{*}{$\begin{array}{l}\text { Culture } \\
\text { result }\end{array}$} & \multirow[t]{2}{*}{ GDH } & \multirow[t]{2}{*}{ CDAB } & \multicolumn{4}{|c|}{ Toxigenic type (no. of isolates) } & \multirow{2}{*}{$\begin{array}{r}\text { Total no. o } \\
\text { isolates (\%) }\end{array}$} \\
\hline & & & $\mathrm{A}+\mathrm{B}+\mathrm{CDT}-$ & A-B+CDT- & $\mathrm{A}+\mathrm{B}+\mathrm{CDT}+$ & A-B-CDT- & \\
\hline Positive & Positive & Positive & 35 & 3 & 1 & 0 & $39(7.7)$ \\
\hline Positive & Positive & Equivocal & 8 & 2 & 0 & I & II (2.2) \\
\hline Positive & Positive & Negative & 18 & 5 & 0 & 11 & $34(6.7)$ \\
\hline Positive & Negative & Negative & 0 & 0 & 0 & 1 & $\mathrm{I}(0.2)$ \\
\hline Negative & Positive & Equivocal & ND & ND & ND & ND & $9(1.8)$ \\
\hline Negative & Positive & Negative & ND & ND & ND & ND & $22(4.4)$ \\
\hline Negative & Negative & Negative & ND & ND & ND & ND & $388(77.0)$ \\
\hline
\end{tabular}

Abbreviations: GDH, glutamate dehydrogenase; CDAB, C. difficile toxin A\&B; CDT, C. difficile binary toxin; ND, not done.

Table 2 Performance of VIDAS GDH and VIDAS CDAB detection for diagnosis of CDI

\begin{tabular}{llll}
\hline Test methods & Sensitivity & Specificity & PPV \\
& $\%(95 \% \mathbf{C I})$ & $\%(95 \% \mathbf{C I})$ & $\begin{array}{l}\text { NPV } \\
\%(95 \% \mathbf{C I})\end{array}$ \\
\hline $\mathrm{GDH}^{\mathrm{a}}$ & $98.8(92.7-99.9)$ & $92.6(89.6-94.8)$ & $73.0(63.8-80.7)$ \\
$\mathrm{CDAB}^{\mathrm{b}}$ & $54.2(42.1-65.8)$ & $100.0(98.9-100.0)$ & $100.0(88.8-100.0)$ \\
\hline
\end{tabular}

Notes: aCompare to culture; ${ }^{\mathrm{C} C}$ Compare to toxigenic culture.

Abbreviations: $\mathrm{GDH}$, glutamate dehydrogenase; CDAB, C. difficile toxin A\&B; PPV, positive predictive value; NPV, negative predictive value. 
Table 3 STs, toxin genotypes and ribotypes of 85 Clostridium difficile clinical isolates

\begin{tabular}{|c|c|c|c|}
\hline $\begin{array}{l}\text { STs } \\
\text { (no. of isolates) }\end{array}$ & Clade & $\begin{array}{l}\text { Toxin genotype } \\
\text { (no. of isolates) }\end{array}$ & $\begin{array}{l}\text { Ribotype } \\
\text { (no. of isolates) }\end{array}$ \\
\hline STI (I) & 2 & $\mathrm{~A}+\mathrm{B}+\mathrm{CDT}+(\mathrm{I})$ & $027(\mathrm{I})$ \\
\hline \multirow[t]{4}{*}{ ST2 (I8) } & I & $\mathrm{A}+\mathrm{B}+\mathrm{CDT}-(\mathrm{I})$ & $014(9)$ \\
\hline & & & $020(7)$ \\
\hline & & & $006(I)$ \\
\hline & & & $432(I)$ \\
\hline \multirow[t]{3}{*}{ ST3 (17) } & I & A-B-CDT- (9) & $009(6)$ \\
\hline & & & $456(3)$ \\
\hline & & $\mathrm{A}+\mathrm{B}+\mathrm{CDT}-(8)$ & $00 \mathrm{I}(8)$ \\
\hline ST4 (I) & I & $\mathrm{A}+\mathrm{B}+\mathrm{CDT}-(\mathrm{I})$ & SDR07 (I) \\
\hline ST8 (I) & I & $\mathrm{A}+\mathrm{B}+\mathrm{CDT}-(\mathrm{I})$ & SDR06 (I) \\
\hline STI7 (2) & I & $\mathrm{A}+\mathrm{B}+\mathrm{CDT}-(2)$ & PUR34 (2) \\
\hline ST27 (I) & 1 & $\mathrm{~A}+\mathrm{B}+\mathrm{CDT}-(\mathrm{I})$ & $039(I)$ \\
\hline ST33 (I) & I & $\mathrm{A}+\mathrm{B}+\mathrm{CDT}-(\mathrm{I})$ & SDR05 (I) \\
\hline \multirow[t]{2}{*}{ ST35 (13) } & I & $\mathrm{A}+\mathrm{B}+\mathrm{CDT}-(13)$ & $046(10)$ \\
\hline & & & SDR09 (3) \\
\hline ST37 (9) & 4 & $\mathrm{~A}-\mathrm{B}+\mathrm{CDT}-(9)$ & $017(9)$ \\
\hline ST42 (I) & I & $\mathrm{A}+\mathrm{B}+\mathrm{CDT}-(\mathrm{I})$ & $106(1)$ \\
\hline ST54 (7) & I & $\mathrm{A}+\mathrm{B}+\mathrm{CDT}-(7)$ & $012(7)$ \\
\hline ST8I (I) & 4 & $\mathrm{~A}-\mathrm{B}+\mathrm{CDT}-(\mathrm{I})$ & PUR09 (I) \\
\hline STI02 (2) & I & $\mathrm{A}+\mathrm{B}+\mathrm{CDT}-(2)$ & PUR02 (2) \\
\hline STIII (I) & I & $\mathrm{A}+\mathrm{B}+\mathrm{CDT}-(\mathrm{I})$ & SDR08 (I) \\
\hline STI29 (I) & I & $\mathrm{A}+\mathrm{B}+\mathrm{CDT}-(\mathrm{I})$ & PURI3 (I) \\
\hline ST205 (2) & 1 & A-B-CDT- (2) & SDR04 (2) \\
\hline ST319 (I) & I & $\mathrm{A}+\mathrm{B}+\mathrm{CDT}-(\mathrm{I})$ & SDR03 (I) \\
\hline ST450 (I $)^{\mathrm{a}}$ & I & A-B-CDT- (I) & SDROI (I) \\
\hline ST45I (I) & I & $\mathrm{A}+\mathrm{B}+\mathrm{CDT}-(\mathrm{I})$ & SDR02 (I) \\
\hline ST452 (I) & I & A-B-CDT- (I) & $010(1)$ \\
\hline ST453 (I $)^{\mathrm{a}}$ & I & $\mathrm{A}+\mathrm{B}+\mathrm{CDT}-(\mathrm{I})$ & $449(I)$ \\
\hline ST454 (I $)^{\mathrm{a}}$ & I & $\mathrm{A}+\mathrm{B}+\mathrm{CDT}-(\mathrm{I})$ & $610(1)$ \\
\hline
\end{tabular}

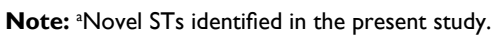

Abbreviations: ST, sequence type; CDT, C. difficile binary toxin.

among nontoxigenic strains (Table 3; Figure 2B). Nine of $10 \mathrm{~A}-\mathrm{B}+\mathrm{CDT}-$ strains belonged to ST37. The only one $\mathrm{A}+\mathrm{B}+\mathrm{CDT}+$ strain belonged to ST1 (Table 3).

In addition, we found that all isolates of the same ribotypes belonged to the same STs, and none of the ribotypes were shared by different STs. Twenty-nine PCR ribotypes were detected among 72 toxigenic strains. The predominant ribotype was RT046 (13.9\%, 10/72), followed by RT014 and RT017 (12.5\%, 9/72, each), RT001 (11.1\%, 8/72), RT012 and RT020 (9.7\%, 7/72, each) (Table 3; Figure 2C). Of note, one $C$. difficile isolate from $\mathrm{ZCH}$ was confirmed to be hypervirulent ribotype 027 (1.4\%, 1/72). Among 13 nontoxigenic strains, ribotypes $009(46.2 \%, 6 / 13)$ and $456(23.1 \%, 3 / 13)$ dominated, and all isolates of these ribotypes belonged to ST3 (Table 3 ).

\section{Clinical severity score of $C D I$ patients}

Seventy-two CDI patients infected by toxigenic $C$. difficile strains were evaluated for CDI severity score. No severity score of 6 was found (Table 4). The average ( \pm SD) severity score was $2.97 \pm 0.90$. There was no difference in severity scores between CDI patients who were CDAB EIA test positive and those who were CDAB EIA test equivocal or negative $(P<0.05)$ (Table 4$)$. However, patients with $\mathrm{A}-\mathrm{B}+\mathrm{CDT}-$ strains had higher severity scores $(3.50 \pm 0.85)$ than patients with $\mathrm{A}+\mathrm{B}+\mathrm{CDT}-$ strains $(2.59 \pm 0.93)(P<0.05)$. In addition, differences in CDI severity scores were found among patients infected by $C$. difficile of different ribotypes and STs (Table 4). ST35 strains showed high severity scores, with a score of $3.69 \pm 0.85$, which was significantly higher than those of ST2, ST3 and ST54 strains $(P<0.05)$, but not significantly different with ST37 ( $P>0.05$, Table 4$)$. In patients with CDI scores of $\geq 4(n=20)$, ribotypes RT046 (35.0\%) and RT014 (20.0\%) were detected more frequently than RT001 (5.0\%) and RT020 (5.0\%). PCR ribotype 027 strain isolated from a gastroenterology patient exhibited high severity with a score of 4 (Table 4 ). There were 4 patients with CDI severity scores of 5 , and half of them belonged to the ST35/046 genotype (Table 4).

\section{Antimicrobial resistance}

The MICs of 6 antimicrobial agents for 85 C. difficile strains are shown in Table 5. All the isolates were susceptible to vancomycin and metronidazole. Thirty out of 85 isolates $(35.3 \%)$ were resistant to erythromycin, clindamycin and ciprofloxacin, and $96.7 \%$ (29/30) of the co-resistant isolates were toxigenic. In contrast, $64.7 \%, 58.8 \%, 97.6 \%$ and $35.3 \%$ of the 85 isolates were resistant to erythromycin, clindamycin, ciprofloxacin and tetracycline, respectively (Table 5). Toxigenic strains showed higher resistance rates to erythromycin, clindamycin and ciprofloxacin than nontoxigenic strains $(P<0.01$, Figure 3A; Table 5). Moreover, there were differences in antimicrobial resistance rates among different STs. For instance, ST35 and ST37 exhibited high resistance rates to erythromycin $(92.3 \%$ and $77.8 \%$, respectively), while ST3 and ST54 showed high resistance rates to clindamycin ( $87.5 \%$ and $85.7 \%$, respectively) (Figure 3B). There was no significant difference in antimicrobial resistance rates of $C$. difficile strains from the 2 hospitals (Figure 2D).

\section{Correlation between fluoroquinolone- resistance and gyrA and gyrB gene mutations}

In order to investigate the mechanism responsible for the high ciprofloxacin resistance, 30 ciprofloxacin-resistant isolates were selected for analyzing the $\operatorname{gyr} A$ and $\operatorname{gyr} B$ 


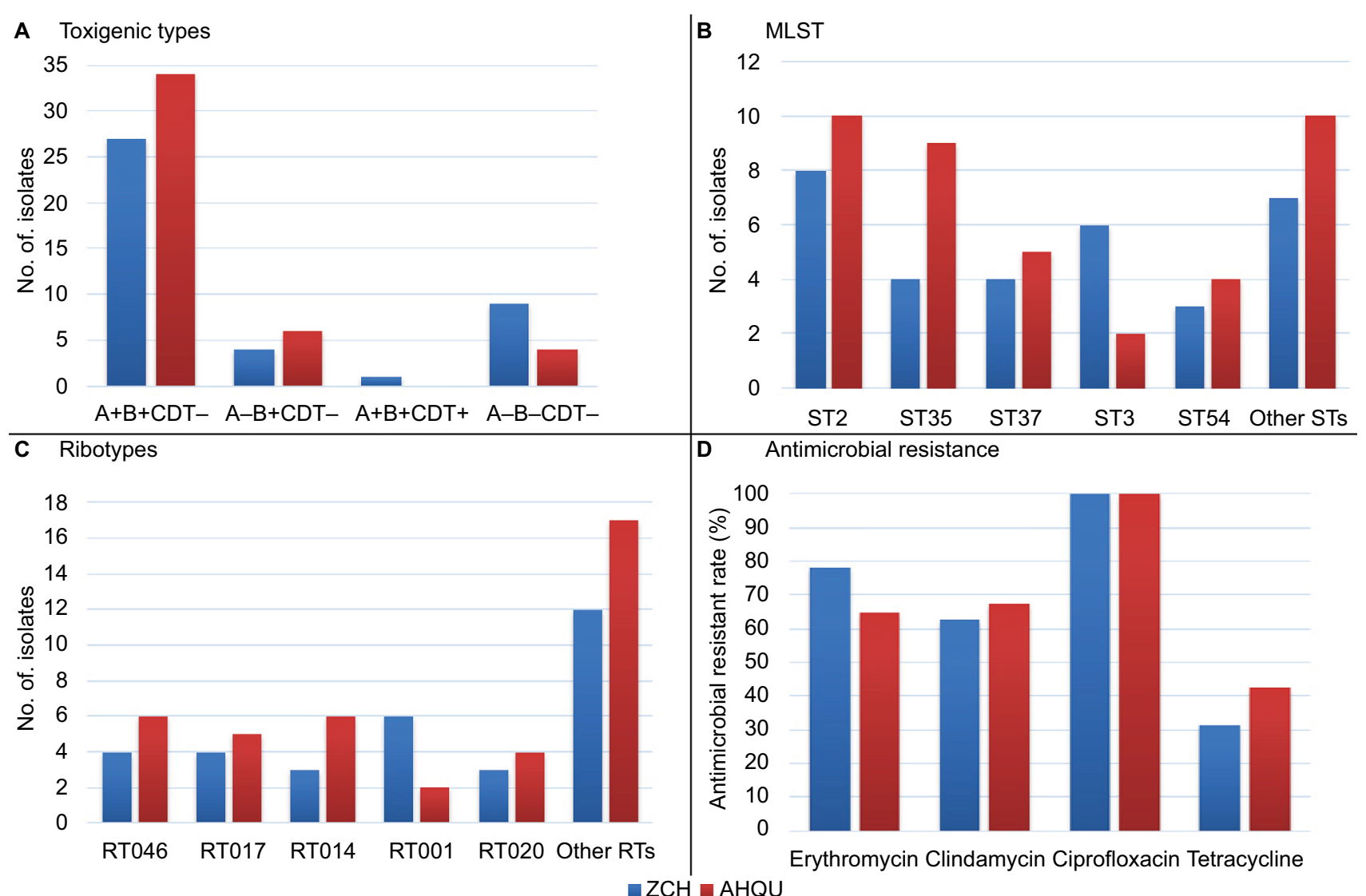

Figure 2 Distribution of toxin genes genotypes among Clostridium difficile isolates $(n=85)(\mathbf{A})$, and MLST STs, PCR ribotypes and antimicrobial resistant rates among toxigenic C. difficile isolates ( $n=72)$ (B-D) from 2 hospitals in China.

Abbreviations: CDT, C. difficile binary toxin; MLST, multilocus sequence typing; ST, sequence type; RT, ribotype; ZCH, Zibo Central Hospital; AHQU, the Affiliated Hospital of Qingdao University; PCR, polymerase chain reaction.

gene sequences (Table 6). Only 10 of the 30 isolates (33.3\%) had GyrA amino acid substitutions (Thr82 $\rightarrow$ Ile), including 4 with GyrB substitutions (Ser366 $\rightarrow$ Ala and/ or Asp426 $\rightarrow$ Val) at the same time (Table 6). The rest 20 $(66.7 \%)$ of the isolates had wild-type gyrA and $g y r B$ gene sequences (Table 6).

We further tested moxifloxacin susceptibility among the 30 isolates and found out that moxifloxacin resistance had good correlation with $g y r A$ and $g y r B$ gene mutations; all isolates that had wild-type $g y r A$ and $g y r B$ genes were moxifloxacin susceptible, while isolates with nonsynonymous mutant gyr $A+/-$ gyrB genes were all moxifloxacin resistant. In addition, isolates with mutations in both $g y r A$ and $g y r B$ genes showed high level resistance to moxifloxacin (MICs of $\geq 32 \mathrm{mg} / \mathrm{L}$ ) compared to isolates having mutation only in gyrA gene (MICs of 8-16 mg/L) (Table 6).

\section{Discussion}

CDI is a significant and increasing public health threat and is regarded as the leading cause of nosocomial diarrhea related to antimicrobial therapy. The morbidity and mortality of CDI have increased substantially in the last decade. ${ }^{25}$ On account of limited laboratory diagnostic capacity and low clinical awareness, lack of data on CDI in China makes it an underestimated problem. ${ }^{9,26,27}$ To our best knowledge, this is the first systematic study on the epidemiology of $C$. difficile from Shandong Province, China.

VIDAS CDAB (bioMérieux) was the first assay approved by China Food and Drug Administration for the laboratory diagnosis of CDI and is to date the most commonly used assay in China. However, our study revealed that $45.8 \%$ of the CDI cases would be missed by using CDAB only. GDH assay, in comparison, had notable high NPV (99.7\%) but low PPV (73.0\%) for diagnosis of CDI. In agreement to previous findings by Cheng et al, ${ }^{26}$ we also recommend the three-step CDI workflow based on combining GDH and CDAB assays and suggest using molecular detection of toxin genes when any discordant results between GDH and CDAB assays are encountered, and this was described first in the updated ESCMID guidelines in 2016. ${ }^{24}$ 
Table 4 Correlation between clinical severity, phenotypes and genotypes in 72 toxigenic Clostridium difficile strains

\begin{tabular}{|c|c|c|c|c|c|}
\hline \multirow[t]{2}{*}{ Phenotype and genotypes } & \multicolumn{5}{|c|}{ CDI severity score } \\
\hline & $2(n=26)$ & $3(n=26)$ & $4(n=16)$ & $5(n=4)$ & Mean \pm SD \\
\hline \multicolumn{6}{|l|}{ EIA phenotype ${ }^{a}$} \\
\hline $\mathrm{GDH}+\mathrm{CDAB}+(\mathrm{n}=39)$ & 15 & 14 & 7 & 3 & $2.95 \pm 0.94$ \\
\hline $\mathrm{GDH}+\mathrm{CDAB}-1 \pm(\mathrm{n}=33)$ & 11 & 12 & 9 & 1 & $3.00 \pm 0.87$ \\
\hline \multicolumn{6}{|l|}{ Toxigenic type } \\
\hline$A+B+C D T-(n=6 I)$ & 25 & 22 & 11 & 3 & $2.59 \pm 0.93$ \\
\hline$A-B+C D T-(n=10)$ & 1 & 4 & 4 & 1 & $3.50 \pm 0.85$ \\
\hline $\mathrm{A}+\mathrm{B}+\mathrm{CDT}+(\mathrm{n}=\mathrm{I})$ & 0 & 0 & 1 & 0 & 4.00 \\
\hline \multicolumn{6}{|l|}{ MLST type } \\
\hline ST2 $(n=18)$ & 8 & 4 & 5 & I & $2.94 \pm 0.99$ \\
\hline ST35 $(n=13)$ & 1 & 4 & 6 & 2 & $3.69 \pm 0.85$ \\
\hline ST37 $(n=9)$ & 3 & 3 & 2 & I & $3.11 \pm 1.05$ \\
\hline ST3 $(n=8)$ & 4 & 3 & 1 & 0 & $2.63 \pm 0.74$ \\
\hline ST54 $(n=7)$ & 3 & 4 & 0 & 0 & $2.57 \pm 0.53$ \\
\hline \multicolumn{6}{|l|}{ PCR ribotype } \\
\hline $046(n=10)$ & 1 & 2 & 5 & 2 & $3.80 \pm 0.92$ \\
\hline $014(n=9)$ & 3 & 2 & 3 & 1 & $3.22 \pm 1.09$ \\
\hline $001 \quad(n=8)$ & 4 & 3 & 1 & 0 & $2.63 \pm 0.74$ \\
\hline $020(n=7)$ & 4 & 2 & 1 & 0 & $2.57 \pm 0.79$ \\
\hline $027(n=I)$ & 0 & 0 & I & 0 & 4.00 \\
\hline
\end{tabular}

Note: ${ }^{\mathrm{G} D H}+\mathrm{CDAB}+$ : toxigenic $C$. difficile strains with $\mathrm{GDH}$ and $\mathrm{CDAB}$ EIA tests positive; $\mathrm{GDH}+\mathrm{CDAB}-/ \pm$, toxigenic $C$. difficile strains, GDH test positive but $C D A B$ EIA test equivocal or negative.

Abbreviations: CDI, C. difficile infection; ElA, enzyme immunoassay; GDH, glutamate dehydrogenase; CDAB, C. difficile toxin A\&B; CDT, C. difficile binary toxin; MLST, multilocus sequence typing; ST, sequence type; PCR, polymerase chain reaction.

Table 5 Antimicrobial resistant rates and MIC ranges for 85 Clostridium difficile clinical isolates

\begin{tabular}{|c|c|c|c|c|c|c|c|c|c|c|c|c|c|}
\hline \multirow{2}{*}{$\begin{array}{l}\text { Antimicrobial } \\
\text { agent }\end{array}$} & \multicolumn{4}{|c|}{ All strains $(n=85)$} & \multicolumn{4}{|c|}{ Toxigenic strains $(n=72)$} & \multicolumn{4}{|c|}{ Non-toxigenic strains $(n=13)$} & \multirow[t]{2}{*}{$P$-value ${ }^{a}$} \\
\hline & $\begin{array}{l}\text { MIC50 } \\
\text { (mg/L) }\end{array}$ & $\begin{array}{l}\text { MIC90 } \\
\text { (mg/L) }\end{array}$ & $\begin{array}{l}\text { Range } \\
\text { (mg/L) }\end{array}$ & $\% \mathbf{R}$ & $\begin{array}{l}\text { MIC50 } \\
\text { (mg/L) }\end{array}$ & $\begin{array}{l}\text { MIC90 } \\
\text { (mg/L) }\end{array}$ & $\begin{array}{l}\text { Range } \\
\text { (mg/L) }\end{array}$ & $\% \mathbf{R}$ & $\begin{array}{l}\text { MIC50 } \\
\text { (mg/L) }\end{array}$ & $\begin{array}{l}\text { MIC90 } \\
\mathrm{mg} / \mathrm{L})\end{array}$ & $\begin{array}{l}\text { Range } \\
\text { (mg/L) }\end{array}$ & $\% \mathbf{R}$ & \\
\hline Vancomycin & 0.5 & I & $0.125-4$ & 0 & 0.5 & 2 & $0.25-4$ & 0 & 0.5 & 1 & $0.125-2$ & 0 & NS \\
\hline Metronidazole & 0.25 & 0.25 & $0.125-1$ & 0 & 0.25 & 0.5 & $0.125-1$ & 0 & 0.25 & 0.25 & $0.25-1$ & 0 & NS \\
\hline Erythromycin & 128 & $>256$ & $0.5->256$ & 64.7 & $>256$ & $>256$ & $0.5->256$ & 70.8 & 64 & 128 & $0.5->256$ & 30.8 & 0.005 \\
\hline Clindamycin & 32 & $>256$ & $0.25->256$ & 58.8 & 64 & $>256$ & $0.5->256$ & 65.3 & 8 & 128 & $0.25->256$ & 23.1 & 0.004 \\
\hline Ciprofloxacin & 64 & 128 & $\mathrm{I}-256$ & 97.6 & 64 & 128 & $8-256$ & 100 & 16 & 128 & $1-128$ & 84.6 & 0.01 \\
\hline Tetracyclin & 0.5 & 32 & $0.125-64$ & 35.3 & 0.5 & 32 & $0.125-64$ & 38.9 & 0.25 & 16 & $0.125-32$ & 15.4 & NS \\
\hline
\end{tabular}

Note: aStatistics for resistant rates of toxigenic strains versus that of nontoxigenic strains.

Abbreviations: MIC, minimum inhibitory concentration; NS, not significant.

In our study, the majority ( $84.7 \%$ ) of the $C$. difficile strains possessed toxin genes, which is similar to previous findings in China, with toxigenic strains accounting for $70 \%-90 \%$ of the strains. ${ }^{7,21,26,28}$ The $C$. difficile isolates from the 2 hospitals exhibited similar epidemic genotype profiles. In addition, the predominant STs in this study, including ST54, ST37, ST3, ST2 and ST35, are also the main epidemic genotypes described in other regions of China (Table 7). ${ }^{7,21,26,28}$ However, geographic diversity was also observed, e.g., the predominant ST2 clone in the present study (25.0\%) was less commonly seen in other regions (up to $13.5 \%$ ) (Table 7). In addition, previous studies in Beijing reveal a shift in epidemic clones over time. Specifically, ST37 was the most common ST (25.7\%) described between the 1980s and 2012 in this locale. However, this ST has become less common as reported in two recent studies (12.2-13.8\%). Meanwhile, ST54 has become more prevalent, rising from $5.7 \%$ to $16.4-18.9 \%$ (Table 7). ${ }^{8,28,29}$ Moreover, remarkable variations in molecular epidemiology of $C$. difficile across different countries worldwide have been observed. For example, in Korea and Japan, ST17 is the predominant type (55.7\% and $21.5 \%$, respectively), followed by ST2 (8.6\% and $10.0 \%$, respectively). ${ }^{30,31}$ However, in Europe, RT027/ST1 is the most prevalent genotype, especially in Western and Eastern Europe. ${ }^{32}$

Of note, RT046/ST35, which has rarely been identified in other countries, but more commonly reported in China, ${ }^{12,33,34}$ 


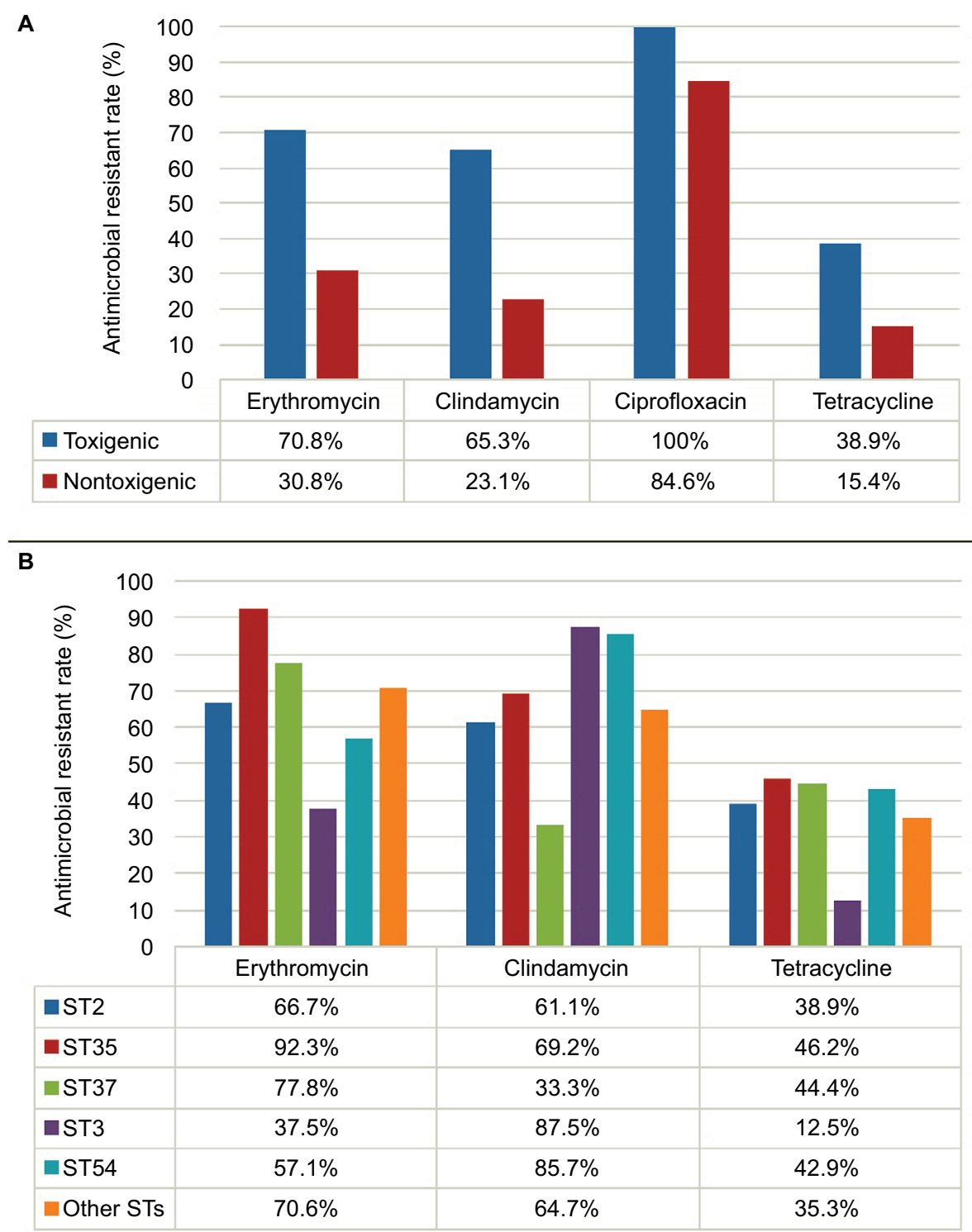

Figure 3 Antimicrobial resistant rates among Clostridium difficile isolates $(\mathbf{A})$ and among different STs of toxigenic $C$. difficile isolates (B). Abbreviation: ST, sequence type.

has scarcely been studied in order to understand its clinical pathogenicity. In this study, RT046/ST35 exhibited higher clinical severity (3.80 \pm 0.92$)$ than other RTs, with high morbidity and severe complications, including pseudomembranous colitis and toxic megacolon, and high resistance rates to erythromycin (90.0\%). These factors suggest that RT046/ ST35 strains could be a major threat in Shandong Province of China and need continued monitoring and implementation of appropriate control measures.

Another interesting finding of this study is the detection of hypervirulent RT027/ST1 strain in this region of China. Similar to the majority of RT027 strains identified worldwide, this isolate was also binary toxin gene positive and had an 18-bp deletion in the $t c d C$ gene. ${ }^{9,11}$ The concerned patient had symptoms of pseudomembranous colitis and was assigned a high-level severity score of 4 . To date, $C$. difficile RT027 cases have only been reported sporadically in China. ${ }^{9,35}$ However, nosocomial outbreaks of $C$. difficile RT027 strains have been reported, ${ }^{36}$ revealing that the threat of RT027 strains might be underestimated, which highlights the need for increasing the laboratory diagnostic capacity for detection of CDI in China and use of molecular typing tools in surveillance programs. ${ }^{37}$

In our study, all the $C$. difficile isolates were susceptible to vancomycin and metronidazole, which is in agreement with other studies, ${ }^{8,31}$ while nearly all $(97.6 \%$. 83/85) the isolates studied were resistant to ciprofloxacin, which was also in accordance with a previous report in China by Cheng et al (ciprofloxacin resistant rates 100\%). ${ }^{8}$ However, our further 
Table 6 Phenotypic and genotypic characteristics of 30 ciprofloxacin-resistant Clostridium difficile strains

\begin{tabular}{|c|c|c|c|c|c|c|c|c|c|}
\hline \multirow[t]{2}{*}{ Isolate } & \multirow{2}{*}{$\begin{array}{l}\text { Toxin } \\
\text { genotype }\end{array}$} & \multirow[t]{2}{*}{ MLST } & \multirow[t]{2}{*}{ Ribotype } & \multicolumn{2}{|l|}{ Moxifloxacin } & \multicolumn{2}{|c|}{ Ciprofloxacin } & \multicolumn{2}{|c|}{ Amino acid substitution } \\
\hline & & & & MIC (mg/L) & Criteria & MIC (mg/L) & Criteria & GyrA & GyrB \\
\hline \multicolumn{10}{|c|}{ Moxifloxacin-resistant strains } \\
\hline S43 & $\mathrm{A}+\mathrm{B}+\mathrm{CDT}+$ & I & 027 & 16 & $\mathrm{R}$ & 128 & $\mathrm{R}$ & Thr82 $\rightarrow$ lle & WT \\
\hline S25 & $\mathrm{A}+\mathrm{B}+\mathrm{CDT}-$ & 3 & 001 & 8 & $\mathrm{R}$ & 64 & $R$ & Thr82 $\rightarrow$ lle & WT \\
\hline $\mathrm{S} 12$ & $\mathrm{~A}+\mathrm{B}+\mathrm{CDT}-$ & 3 & 001 & 16 & $\mathrm{R}$ & 64 & $R$ & Thr82 $\rightarrow$ lle & WT \\
\hline S65 & $\mathrm{A}+\mathrm{B}+\mathrm{CDT}-$ & 17 & PUR34 & 32 & $\mathrm{R}$ & 64 & $\mathrm{R}$ & Thr82 $\rightarrow$ lle & Ser $366 \rightarrow$ Ala \\
\hline S32 & $\mathrm{A}+\mathrm{B}+\mathrm{CDT}-$ & 35 & 046 & 16 & $\mathrm{R}$ & 32 & $\mathrm{R}$ & Thr82 $\rightarrow$ lle & WT \\
\hline S8I & $\mathrm{A}+\mathrm{B}+\mathrm{CDT}-$ & 35 & 046 & 16 & $\mathrm{R}$ & 128 & $\mathrm{R}$ & Thr82 $\rightarrow$ lle & WT \\
\hline S74 & $\mathrm{A}-\mathrm{B}+\mathrm{CDT}-$ & 37 & 017 & 64 & $\mathrm{R}$ & 128 & $R$ & Thr82 $\rightarrow$ lle & Ser $366 \rightarrow$ Ala \\
\hline S53 & $\mathrm{A}-\mathrm{B}+\mathrm{CDT}-$ & 37 & 017 & 64 & $\mathrm{R}$ & 128 & $R$ & Thr82 $\rightarrow$ lle & Ser $366 \rightarrow$ Ala \\
\hline S5 & $\mathrm{A}-\mathrm{B}+\mathrm{CDT}-$ & 81 & PUR09 & 64 & $\mathrm{R}$ & 128 & $\mathrm{R}$ & Thr82 $\rightarrow$ lle & Ser366 $\rightarrow$ Ala, Asp $426 \rightarrow$ Val \\
\hline SI6 & $\mathrm{A}+\mathrm{B}+\mathrm{CDT}-$ & 111 & SDR08 & 16 & $\mathrm{R}$ & 128 & $R$ & Thr82 $\rightarrow$ lle & WT \\
\hline \multicolumn{10}{|c|}{ Moxifloxacin-susceptible strains } \\
\hline S42 & $\mathrm{A}+\mathrm{B}+\mathrm{CDT}-$ & 2 & 014 & 0.25 & S & 32 & $\mathrm{R}$ & WT & WT \\
\hline S2I & $\mathrm{A}+\mathrm{B}+\mathrm{CDT}-$ & 2 & 014 & 0.25 & S & 64 & $\mathrm{R}$ & WT & WT \\
\hline S2 & $\mathrm{A}+\mathrm{B}+\mathrm{CDT}-$ & 2 & 014 & 0.25 & S & 64 & $\mathrm{R}$ & WT & WT \\
\hline S8 & $\mathrm{A}+\mathrm{B}+\mathrm{CDT}-$ & 2 & 020 & 0.5 & S & 64 & $\mathrm{R}$ & WT & WT \\
\hline S6I & $\mathrm{A}+\mathrm{B}+\mathrm{CDT}-$ & 2 & 020 & 0.5 & S & 32 & $R$ & WT & WT \\
\hline S83 & $\mathrm{A}+\mathrm{B}+\mathrm{CDT}-$ & 2 & 006 & 1 & $S$ & 128 & $R$ & WT & WT \\
\hline SI4 & $\mathrm{A}+\mathrm{B}+\mathrm{CDT}-$ & 2 & 432 & 1 & S & 128 & $R$ & WT & WT \\
\hline S24 & $\mathrm{A}-\mathrm{B}-\mathrm{CDT}-$ & 3 & 009 & 0.25 & $S$ & 64 & $R$ & WT & WT \\
\hline S55 & $\mathrm{A}-\mathrm{B}-\mathrm{CDT}-$ & 3 & 456 & 0.25 & S & 64 & $R$ & WT & WT \\
\hline S47 & $\mathrm{A}+\mathrm{B}+\mathrm{CDT}-$ & 4 & SDR07 & 0.25 & $S$ & 64 & $R$ & WT & WT \\
\hline S7I & $\mathrm{A}+\mathrm{B}+\mathrm{CDT}-$ & 8 & SDR06 & 0.5 & S & 128 & $R$ & WT & WT \\
\hline S9 & $\mathrm{A}+\mathrm{B}+\mathrm{CDT}-$ & 27 & 039 & 0.5 & $S$ & 128 & $R$ & WT & WT \\
\hline SII & $\mathrm{A}+\mathrm{B}+\mathrm{CDT}-$ & 33 & SDR05 & 2 & $S$ & 64 & $R$ & WT & WT \\
\hline S49 & $\mathrm{A}+\mathrm{B}+\mathrm{CDT}-$ & 35 & 046 & 2 & S & 64 & $R$ & WT & WT \\
\hline S67 & $\mathrm{A}+\mathrm{B}+\mathrm{CDT}-$ & 35 & SDR09 & 0.25 & $S$ & 32 & $R$ & WT & WT \\
\hline S20 & $\mathrm{A}+\mathrm{B}+\mathrm{CDT}-$ & 42 & 106 & 0.25 & $S$ & 32 & $R$ & WT & WT \\
\hline S4 & $\mathrm{A}+\mathrm{B}+\mathrm{CDT}-$ & 54 & 012 & 0.25 & S & 32 & $\mathrm{R}$ & WT & WT \\
\hline S73 & $\mathrm{A}+\mathrm{B}+\mathrm{CDT}-$ & 54 & 012 & 0.25 & $S$ & 64 & $\mathrm{R}$ & WT & WT \\
\hline S48 & $\mathrm{A}+\mathrm{B}+\mathrm{CDT}-$ & 102 & PUR02 & 1 & $S$ & 32 & $\mathrm{R}$ & WT & WT \\
\hline S19 & $\mathrm{A}+\mathrm{B}+\mathrm{CDT}-$ & 129 & PURI3 & 0.5 & $S$ & 64 & $\mathrm{R}$ & WT & WT \\
\hline
\end{tabular}

Abbreviations: MLST, multilocus sequence typing; MIC, minimum inhibitory concentration; CDT, C. difficile binary toxin; S, susceptible; R, resistant; WT, wild-type.

Table 7 Review of Clostridium difficile studies, ranged by latitude from north to south in mainland China

\begin{tabular}{|c|c|c|c|c|c|c|c|c|c|}
\hline \multirow[t]{2}{*}{ No. } & \multirow[t]{2}{*}{ Geographic } & \multirow[t]{2}{*}{ Year } & \multicolumn{3}{|c|}{ MLST prevalence } & \multicolumn{3}{|c|}{ RTs prevalence } & \multirow[t]{2}{*}{ Reference } \\
\hline & & & Ist (\%) & 2nd (\%) & 3rd (\%) & I st (\%) & 2nd (\%) & 3rd (\%) & \\
\hline I & Beijing & $1980 s-2012$ & ST37 (25.7) & ST35 (18.6) & ST3 (I7.I) & & & & 29 \\
\hline 2 & Beijing & $2012-2015$ & ST54 (16.4) & ST3 (I4.7) & ST37 (13.8) & & & & 8 \\
\hline 3 & Beijing & $2014-2015$ & ST54 (I8.9) & ST2 (13.5) & ST37 (12.2) & & & & 28 \\
\hline 4 & Hebei & $2013-2014$ & ST54 (29.2) & ST3 (25.7) & ST35 (10.6) & & & & 39 \\
\hline 5 & Shandong & $2016-2017$ & ST2 (25.0) & ST35 (18.1) & ST37 (12.5) & RT046 (13.9) & RTOI4 (I2.5) & RT0I7 (12.5) & This study \\
\hline 6 & Jiangsu & $2015-2016$ & ST54 (32.8) & ST3 (16.4) & ST35 (I3.I) & & & & 40 \\
\hline 7 & Shanghai & $2012-2013$ & ST8I (18.8) & ST54 (I4.I) & ST $37(12.5)$ & & & & 41 \\
\hline 8 & Shanghai & $2012-2013$ & & & & RTOI7 (2I.0) & RTOI2 (I7.3) & RTH (16.7) & 14 \\
\hline 9 & Sichuan & $2012-2013$ & ST3 (16.I) & ST35 (I2.9) & ST54 (I2.9) & & & & 34 \\
\hline 10 & Zhejiang & $2009-2011$ & ST54 (23.0) & ST35 (19.3) & ST37 (10.0) & & & & 12 \\
\hline II & Zhejiang & $2012-2013$ & & & & RT006 (55.0) & RT002 (30.0) & RTOI4 (I0.0) & 42 \\
\hline 12 & Zhejiang & 2013 & & & & RTOI7 (50.0) & RT00I (26.8) & RTOI4 (I4.6) & 43 \\
\hline 13 & Zhejiang & $2012-2015$ & ST37 (I6.5) & ST3 (I6.3) & ST54 (I2.9) & & & & 7 \\
\hline 14 & Hunan & 2009-2010 & & & & RT0I7 (48.0) & RT046 (14.0) & RTOI2 (14.0) & 44 \\
\hline
\end{tabular}

Abbreviations: MLST, multilocus sequence typing; RT, ribotype; ST, sequence type. 
investigations showed that there were significant differences between moxifloxacin and ciprofloxacin activities against $C$. difficile isolates, and chromosomal mutations in gyr $A$ and gyrB genes were associated with moxifloxacin rather than ciprofloxacin susceptibilities. Moreover, an observational study in England showed that the incidence of CDI declined by about $80 \%$ by restricting national fluoroquinolone prescribing and elimination of fluoroquinolone-resistant isolates. This highlights the importance of fluoroquinolone restriction in the control of CDI. ${ }^{38}$ Therefore, antimicrobial stewardship is a key component in CDI prevention.

\section{Conclusion}

The study is the first systematic study on CDI in Shandong Province, China. Our findings highlight the importance of calls for improved efforts in the development of laboratory diagnostic capacity for CDIs in China, including utilizing rational and effective algorithms. Continued regional and national monitoring of CDIs, including molecular epidemiology surveillance, and implementation of comprehensive and systemic control strategies, including antimicrobial stewardships, are urgently needed in China.

\section{Acknowledgments}

The authors thank Yan Zhao of Zibo Central Hospital for sample collection, Yan Jin and Chun-Hong Shao of the Provincial Hospital Affiliated to Shandong University for the technical support and Fanrong Kong of Westmead Hospital and Ying-Chun Xu of Peking Union Medical College Hospital for critically reviewing the manuscript. This study was financially supported by a Natural Science Foundation of China (grant number 81501807) and a PUMCH Science Fund for Junior Faculty (grant number pumch-2016-1.2).

\section{Author contributions}

All authors contributed toward data analysis, drafting and revising the paper and agree to be accountable for all aspects of the work.

\section{Disclosure}

The authors report no conflicts of interest in this work.

\section{References}

1. Rupnik M, Wilcox MH, Gerding DN. Clostridium difficile infection: new developments in epidemiology and pathogenesis. Nat Rev Microbiol. 2009;7(7):526-536.

2. Persson S, Torpdahl M, Olsen KE. New multiplex PCR method for the detection of Clostridium difficile toxin $\mathrm{A}(t c d A)$ and toxin $\mathrm{B}(t c d B)$ and the binary toxin $(c d t A / c d t B)$ genes applied to a Danish strain collection. Clin Microbiol Infect. 2008;14(11):1057-1064.
3. Jones AM, Kuijper EJ, Wilcox MH. Clostridium difficile: A European perspective. J Infect. 2013;66(2):115-128.

4. Lessa FC, Winston LG, McDonald LC, Emerging Infections Program CdST. Burden of Clostridium difficile infection in the United States. N Engl J Med. 2015;372(24):2369-2370.

5. Desai K, Gupta SB, Dubberke ER, Prabhu VS, Browne C, Mast TC. Epidemiological and economic burden of Clostridium difficile in the United States: estimates from a modeling approach. BMC Infect Dis. 2016;16:303.

6. Griffiths D, Fawley W, Kachrimanidou M, et al. Multilocus sequence typing of Clostridium difficile. J Clin Microbiol. 2010;48(3):770-778.

7. Jin D, Luo Y, Huang C, et al. Molecular epidemiology of Clostridium difficile infection in hospitalized patients in eastern China. J Clin Microbiol. 2017;55(3):801-810.

8. Cheng JW, Xiao M, Kudinha T, et al. Molecular epidemiology and antimicrobial susceptibility of Clostridium difficile isolates from a university teaching hospital in China. Front Microbiol. 2016;7:1621.

9. Cheng JW, Xiao M, Kudinha T, et al. The first two Clostridium difficile ribotype 027/ST1 isolates identified in Beijing, China - an emerging problem or a neglected threat? Sci Rep. 2016;6:18834.

10. Knight DR, Elliott B, Chang BJ, Perkins TT, Riley TV. Diversity and evolution in the genome of Clostridium difficile. Clin Microbiol Rev. 2015;28(3):721-741.

11. Elliott B, Androga GO, Knight DR, Riley TV. Clostridium difficile infection: evolution, phylogeny and molecular epidemiology. Infect Genet Evol. 2017;49:1-11.

12. Chen YB, Gu SL, Wei ZQ, et al. Molecular epidemiology of Clostridium difficile in a tertiary hospital of China. J Med Microbiol. 2014;63(Pt 4):562-569.

13. Lv Z, Peng GL, Su JR. Factors associated with Clostridium difficile diarrhea in a hospital in Beijing, China. Braz J Med Biol Res. 2014;47(12): 1085-1090.

14. Gao Q, Wu S, Huang H, et al. Toxin profiles, PCR ribotypes and resistance patterns of Clostridium difficile: a multicentre study in China, 2012-2013. Int J Antimicrob Agents. 2016;48(6):736-739.

15. Lidan C, Linhai L, Yang L, Zhaohui S, Xiaoyan H, Yuling S. Molecular characterization and antimicrobial susceptibility of $t c d A$-negative Clostridium difficile isolates from Guangzhou, China. Diagn Microbiol Infect Dis. 2016;84(4):361-365.

16. Kato H, Kato N, Katow S, Maegawa T, Nakamura S, Lyerly DM. Deletions in the repeating sequences of the toxin A gene of toxin A-negative, toxin B-positive Clostridium difficile strains. FEMS Microbiol Lett. 1999;175(2):197-203.

17. Curry SR, Marsh JW, Muto CA, O’Leary MM, Pasculle AW, Harrison LH. $t c d C$ genotypes associated with severe TcdC truncation in an epidemic clone and other strains of Clostridium difficile.J Clin Microbiol. 2007;45(1):215-221.

18. Indra A, Huhulescu S, Schneeweis M, et al. Characterization of Clostridium difficile isolates using capillary gel electrophoresis-based PCR ribotyping. J Med Microbiol. 2008;57(Pt 11):1377-1382.

19. Clinical and Laboratory Standards Institute (CLSI). M11-A8. Methods for Antimicrobial Susceptibility Testing of Anaerobic Bacteria; Approved Standard - Eighth Edition. Wayne, PA: Clinical and Laboratory Standards Institute; 2012.

20. Clinical and Laboratory Standards Institute (CLSI). M100. Performance Standards for Antimicrobial Susceptibility Testing. 27th ed. Wayne, PA: Clinical and Laboratory Standards Institute; 2017.

21. Huang $\mathrm{H}, \mathrm{Wu} \mathrm{S}$, Wang $\mathrm{M}$, et al. Clostridium difficile infections in a Shanghai hospital: antimicrobial resistance, toxin profiles and ribotypes. Int J Antimicrob Agents. 2009;33(4):339-342.

22. Drudy D, Quinn T, O’Mahony R, KynAe L, O'Gaora P, Fanning S. High-level resistance to moxifloxacin and gatifloxacin associated with a novel mutation in $g y r B$ in toxin-A-negative, toxin-B-positive Clostridium difficile. J Antimicrob Chemother. 2006;58(6):1264-1267.

23. Cohen SH, Gerding DN, Johnson S, et al. Clinical practice guidelines for Clostridium difficile infection in adults: 2010 update by the Society for Healthcare Epidemiology of America (SHEA) and the Infectious Diseases Society of America (IDSA). Infect Control Hosp Epidemiol. 2010;31(5):431-455. 
24. Crobach MJ, Planche T, Eckert C, et al. European Society of Clinical Microbiology and Infectious Diseases: update of the diagnostic guidance document for Clostridium difficile infection. Clin Microbiol Infect. 2016;22(Suppl 4):S63-S81.

25. Leffler DA, Lamont JT. Clostridium difficile infection. New Engl J Med. 2015;372(16):1539-1548.

26. Cheng JW, Xiao M, Kudinha T, et al. The role of glutamate dehydrogenase $(\mathrm{GDH})$ testing assay in the diagnosis of Clostridium difficile infections: a high sensitive screening test and an essential step in the proposed laboratory diagnosis workflow for developing countries like China. PloS One. 2015;10(12):e0144604.

27. Galaydick J, Xu Y, Sun L, et al. Seek and you shall find: prevalence of Clostridium difficile in Wuhan, China. Am J Infect Control. 2015;43(3):301-302.

28. Wang R, Chen HX, Song LJ, Shen YY, Luo YP. Molecular epidemiology and antimicrobial susceptibility of Clostridium difficile isolated from the Chinese People's Liberation Army General Hospital in China. Int J Infect Dis. 2018;67:86-91.

29. Du P, Cao B, Wang J, et al. Sequence variation in $t c d A$ and $t c d B$ of Clostridium difficile: ST37 with truncated $t c d A$ is a potential epidemic strain in China. J Clin Microbiol. 2014;52(9):3264-3270.

30. Nicholas A, Kim YK, Lee WK, et al. Molecular epidemiology and antimicrobial susceptibility of Clostridium difficile isolates from two Korean hospitals. PloS One. 2017;12(3):e0174716.

31. Kuwata Y, Tanimoto S, Sawabe E, et al. Molecular epidemiology and antimicrobial susceptibility of Clostridium difficile isolated from a university teaching hospital in Japan. Eur J Clin Microbiol Infect Dis. 2015;34(4):763-772.

32. Davies KA, Ashwin H, Longshaw CM, et al, EUCLID Study Group. Diversity of Clostridium difficile PCR ribotypes in Europe: results from the European, multicentre, prospective, biannual, point-prevalence study of Clostridium difficile infection in hospitalised patients with diarrhoea (EUCLID), 2012 and 2013. Euro Surveill. 2016;21(29).

33. Bauer MP, Notermans DW, van Benthem BH, et al. Clostridium difficile infection in Europe: a hospital-based survey. Lancet. 2011;377(9759): $63-73$
34. Wang X, Cai L, Yu R, Huang W, Zong Z. ICU-onset Clostridium difficile infection in a university hospital in China: a prospective cohort study. PloS One. 2014;9(11):e111735.

35. Wang P, Zhou Y, Wang Z, Xie S. Identification of Clostridium difficile ribotype 027 for the first time in mainland China. Infect Control Hosp Epidemiol. 2014;35(1):95-98.

36. Jia H, Du P, Yang H, et al. Nosocomial transmission of Clostridium difficile ribotype 027 in a Chinese hospital, 2012-2014, traced by whole genome sequencing. BMC Genomics. 2016;17:405.

37. Krutova M, Nyc O, Matejkova J, Kuijper EJ, Jalava J, Mentula S. The recognition and characterisation of Finnish Clostridium difficile isolates resembling PCR-ribotype 027. J Microbiol Immunol Infect. 2017;pii:S1684-1182(17)30051-8.

38. Dingle KE, Didelot X, Quan TP, et al. Effects of control interventions on Clostridium difficile infection in England: an observational study. Lancet Infect Dis. 2017;17(4):411-421.

39. Tian TT, Zhao JH, Yang J, et al. Molecular characterization of Clostridium difficile isolates from human subjects and the environment PloS One. 2016;11(3):e0151964.

40. Yan J, Liang J, LvT, et al. Epidemiology of Clostridium difficile in a county level hospital in China. Jundishapur J Microbiol. 2017;10(6):e14376.

41. Zhou FF, Wu S, Klena JD, Huang HH. Clinical characteristics of Clostridium difficile infection in hospitalized patients with antibioticassociated diarrhea in a university hospital in China. Eur J Clin Microbiol Infect Dis. 2014;33(10):1773-1779.

42. Zhu S, Zhang L, Zhang C, Chen X, Chen Q, Li Z. Comparison of polymerase chain reaction ribotyping, toxinotyping and nutritional aspects of toxin production of Clostridium difficile strains. Biomed Rep. 2014;2(4):477-480.

43. Fang WJ, Jing DZ, Luo Y, et al. Clostridium difficile carriage in hospitalized cancer patients: a prospective investigation in eastern China. BMC Infect Dis. 2014;14:523.

44. Hawkey PM, Marriott C, Liu WE, et al. Molecular epidemiology of Clostridium difficile infection in a major Chinese hospital: an underrecognized problem in Asia? J Clin Microbiol. 2013;51(10): 3308-3313. 


\section{Supplementary material}

Table SI Antimicrobial resistant breakpoint of six antimicrobial agents used in the study

Antimicrobial agents Resistant interpretive criteria $(\mu \mathrm{g} / \mathrm{mL})$

Erythromycin $\geq 8^{\mathrm{b}}$

Ciprofloxacin

$\geq 8^{\text {b }}$

Clindamycin

$\geq 8^{\mathrm{a}}$

Metronidazole

$\geq 32^{\mathrm{a}}$

Tetracycline

$\geq 16^{\mathrm{a}}$

Vancomycin

$\geq 32^{\mathrm{b}}$

Notes: ${ }^{a}$ Breakpoints per CLSI document MI00. ${ }^{20}$ breakpoints per Huang et al. ${ }^{21}$

Infection and Drug Resistance is an international, peer-reviewed openaccess journal that focuses on the optimal treatment of infection (bacterial, fungal and viral) and the development and institution of preventive strategies to minimize the development and spread of resistance. The journal is specifically concerned with the epidemiology of antibiotic resistance and the mechanisms of resistance development and diffusion in both hospitals and the community. The manuscript management system is completely online and includes a very quick and fair peerreview system, which is all easy to use. Visit http://www.dovepress.com/ testimonials.php to read real quotes from published authors.

Submit your manuscript here: https://www.dovepress.com/infection-and-drug-resistance-journal 